EESTI NSV TEADUSTE AKADEEMIA TOIMETISED. XIII KÖIDE

FOOSIKA-MATEMAATIKA- JA TEHNIKATEADUSTE SEERIA. 1964, NR. 1

ИЗВЕСТИЯ АҚАДЕМИИ НАУК ЭСТОНСКОН ССР. ТОМ ХІІ

СЕРИЯ ФИЗНКО-МАТЕМАТИЧЕСКИХ И ТЕХНИЧЕСКИХ НАУК. 1964, № I

\title{
LOODUSLIKE JA KEEMILISTE KIUDAINETE IDENTIFITSEERIMISEST GAASIKROMATOGRAAFILISEL MEETODIL
}

\author{
O. KIRRET,
}

Eesti NSV Teaduste Akadeemia korrespondentliige

\section{E. KULLIK}

Keemiliste tehis- ja sünteetiliste kiudainete ulatuslikust tootmisest ning nende liikide mitmekesisusest tingituna kerkib järjest uusi nõudeid analüütikutele, kes tegelevad nende kvalitatiivse ja kvantitatiivse määramisega. On loodud mitmeid meetodeid keemiliste ja looduslike kiudainete segude süstemaatiliseks analüüsimiseks.

Need analüüsimeetodid on tänapäeval sama keerukad kui klassikalises analüïtilises keemias tuntud katioonirühmade analüüs $\left[{ }^{1}, 2,3,\right]$.

Kiudainete süstemaatilisele analüüsile eelneb terve rida eelkatseid, nagu põletusproov, kuivdestillatsioon, nende töötlemine nii kontsentreeritud väävelhappe, plii leeliselahuse, sipelgahappe, atsetooni kui ka fenooliga.

Neist eelkatseist on üks lihtsamaid pōletusproov, mille abil varem saadi looduslike kiudainete kohta küllaltki ammendavaid andmeid. Keemiliste, eeskätt paljude keemiliselt ehituselt ja omadustelt erinevate kiudainete kasutuselevõtuga aga muutub üha raskemaks măärata põletusproovi abil ühe või teise sünteetilise kiudaine esinemist kiudainete segus. Põletusproove tuleb nüüd teostada erilise hoolikusega, uurides põlemise iseloomu, lõhna ja jäăki, kusjuures järeldusi tuleb teha organoleptilistel vaatlustel saadud andmete alusel.

Käesoleva artikli autorid seadsid endale ülesandeks välja selgitada, millisel määral on vôimalik kiudainete pürolüüsi uurimiseks inertgaaside keskkonnas rakendada gaasikromatograafiat ja teha pürolüüsi produktidest lähtudes kiudainete kvalitatiivset analüüsi.

Gaasikromatograafia on viimastel aastatel leidnud kasutamist orgaaniliste, metallorgaaniliste ja kõrgmolekulaarsete ainete pürolüüsi produktide uurimisel. Selle meetodi eeliseks on uuritava aine minimaalne vajadus $(2-10 \mathrm{mg})$, olenevalt kromatograafi tundlikkusest. Mikropürolüüs võimaldab ühelt poolt uurida ainete termilist stabiilsust ja termilise lagunemise kineetikat ning mäărata tekkinud produkte nii kvalitatiivselt kui ka kvantitatiivselt, teiselt poolt võib aga uuritavat ainet pürolüüsil saadud kromatogrammide järgi identifitseerida. Senini on gaasikromatograafia abil süstemaatiliselt uuritud pürolüüsil tekkivaid produkte, olenevalt pürolüüsi tingimustest mõningate polümeeride puhul [ $\left.{ }^{4-11}\right]$. Andmed aga puuduvad põhiliselt keemiliste ja looduslike kiudainete kohta.

Käesoleva uurimuse autorid pürolüüsisid keemilisi ja looduslikke kiudaineid eesmär giga identifitseerida kromatogrammide järgi kiudaine liike. Looduslikest kiudainetest oli vaatluse all vill, siid ja puuvill, keemilistest - lavsaan, nitron, vinool, kloriin, kapron, önant, aniid, polüetüleen (läätsekujulisest toorainest), polüpropüleen, viskoos ja atsetaat.

\section{Eksperimentaalne osa}

Pürolüüsi produktide uurimiseks kasutati laboratoorset gaasikromatograafi XЛ-3, milles vedelate proovide sisestamiseks ettenähtud sõlm oli asendatud pürolüüsiblokiga; see võimaldas kiudude pürolüüsi teostada kromatograafi kandegaasi voolus. 
Pürolüüsiblokk (joon. 1) koosneb vasest valmistatud silindrilisest korpusest 1 , mis on suletav keermestatud korgiga 2. Korgi tihendina kasutati fluorplasti 3 . Seda läbivate juhtmete klemmide 4 külge kinnitati 4,5-millimeetrise läbimõõduga pürolüüsi küttespiraal 5 . Spiraali üks haru isoleeriti portselantorukesega 6 .

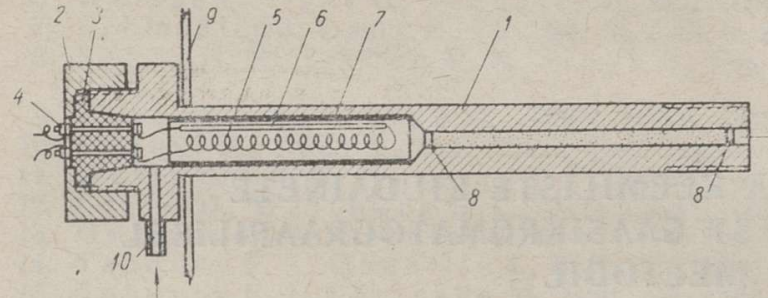

Joon. 1. Pürolüüsiblokk.

Spiraal valmistati 0,4-millimeetrise läbimõõduga kroomnikkeltraadist, mille kogutakistus oli 3,0 oomi. Pürolüüsi temperatuuri reguleerimiseks ühendati küttespiraal autotrafoga, mida reguleerimise täpsuse suurendamiseks toideti 30 -voldise pingega. Spiraali temperatuur oli termopaari abil pinge järgi kalibreeritud. Spiraali isoleerimi-

seks korpusest ümbritseti ta kvartstoruga 7. Filtriks, mis väldib tahkete osakeste sattumist ühendustorustikku ja kolonni, oli bloki tagumises osas vaskvõrguga 8 eraldatud peenendatud tellis (50-70 mesh). Kandegaas siseneb pürolüüsiblokki ava 10 kaudu, mis läbib vahetult enne blokki asetseva vedela faasi sisestamise seadise. Pürolüüsiblokk paikneb kromatograafi esipaneelil 9, tagumine osa aga vedela faasi ülekuumendajas.

5-10 mg kuivatamata kiudainet asetati 2,5-millimeetrise läbimõõduga kvartstorukesse, et vältida küttespiraali võimalikku katalüütilist mõju. Toruke koos prooviga paigutati küttespiraali keskele ning juhiti kandegaasi läbi bloki, kuni kromatograafi nulljoone stabiliseerumiseni. Spiraali kuumutati 60 sekundit, mille vältel saadi pürolüüsiks nõutav temperatuur.
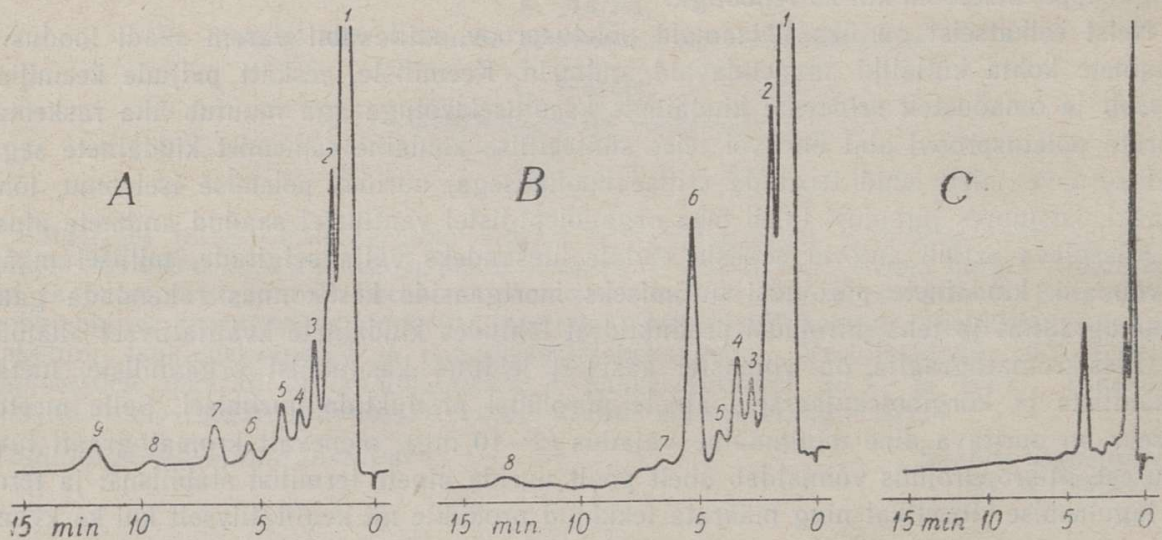

Joon. 2. Pürolüüsi kromatogrammid: A - polüetüleen, kolonni täidiseks polüetüleenglükool 4000/diatomiittellis (50-70 mesh); B - polüpropüleen, kolonni täidiseks polüetüleenglükool $4000 /$ diatomiittellis $(50-70 \mathrm{mesh}) ; \mathrm{C}$ - polüpropüleen, kolonni täidiseks «Tween $85 » / \ll$ Chromosorb W» (45-60 mesh).

Pürolüüsitingimuste valikul lähtuti tekkinud produktide analüüsi kestusest ja sellest, et saadavad kromatogrammid oleksid hästi dešiireeritavad, Pürolüüsi temperaiuuri valikul arvestati, et kõrgemal temperatuuril tekib rohkem produkte, mis paremini iseloomustavad uuritavaid kiudusid. Iga analüüsi lōpul süstiti kromatograafi etaloonainena bensooli ning arvutati kromatogrammi iseloumustavamad piigid.

Kolonni täidise tähtsus selgub joonisel 2 esitatud polüpropüleeni pürolüüsi kromatogrammidest. Polüetüleenglükool 4000/diatomiittellistäidisega kolonni kasutamisel (joon. 2: B) saadi rohkem iseloomustavaid piike kui «Tween $85 \% /$ «Chromosorb W» (45-60 mesh) täidisega kolonni puhul (joon. 2: C). 
Pikemate kolonnide kasutamine annab küll selektiivsemaid tulemusi, kuid pikendab tunduvalt analüüsi kestust. Joonisel $4: \mathrm{F}$ on esitatud vinooli pürolüüsi produktide kromatogramm, mis saadi 2-meetrise polüetüleenglükooltäidisega kolonni kasutades. Võrdluseks näeme joonisel 3 vinooli kromatogrammi sama täidisega 3-meetrise kolonni puhul, kusjuures analüüsi kestus pikenes 20-1t minutilt 35-le. Numereeritud piigid on samad mis 2-meetrise kolonni kasutamisel. Numereerimata piigid on tingitud pikema kolonni paremast eraldamisvôimest. Kiudainete pürolüüsil oli

kolonni pikkus, $\mathrm{m}$

kolonni sisemine läbimõōt, mm

kandegaas

kolonni täidis

täidise tahke ja vedela faasi suhe

kandegaasi kiirus, $\mathrm{ml} / \mathrm{min}$.

kolonni temperatuur, ${ }^{\circ} \mathrm{C}$

pürolüüsi kestus, sek.

pürolüüsi temperatuur, ${ }^{\circ} \mathrm{C}$
2,0 ,

2,8 ,

heelium,

polüetüleenglükool

4000 /diatomiittellis

(50-70 mesh),

$80: 20$,

50 ,

100

$60 \mathrm{ja}$

900.

Tabel 1

\section{Kiudainete pürolüüsi kromatogrammide iseloomustavamate piikide orienteeruvad kaugused bensooli suhtes*}

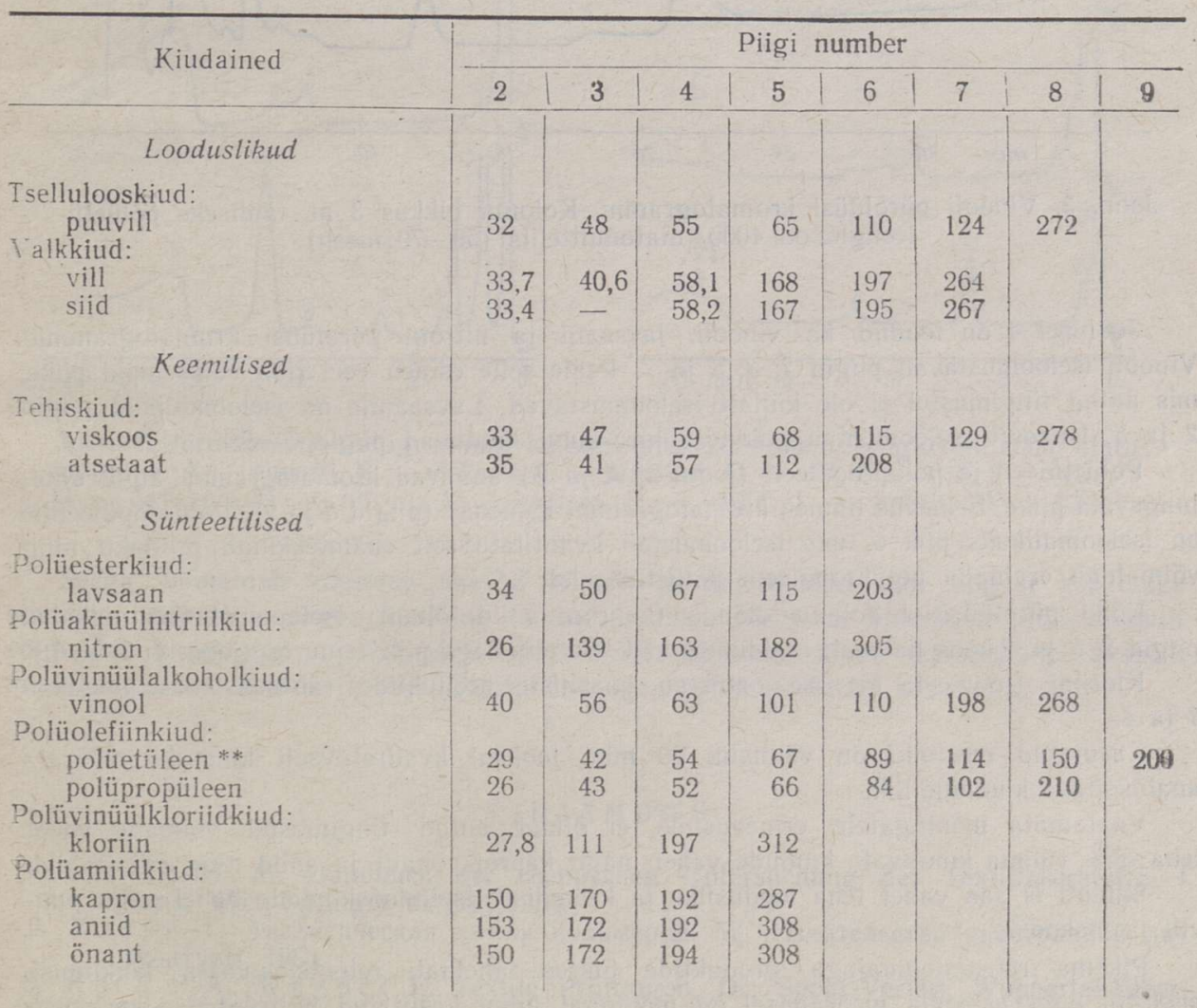

* Täidiseks polüetüleenglükool 4000/ diatomiittellis, kolonni pikkus $2 \mathrm{~m}$.

** Pürolüüsiks kasutati Ohtinski tehase läätsekujulist polüetüleeni. 


\section{Pürolüüsi tulemused}

Et eesmärgiks oli selgitada, millisel määral on vôimalik kiudainete pürolüüsi produktide kromatogramme kasutada kiudude kvalitatiivseks.määramiseks, siis ei ole identifitseeritud pürolüüsi eriprodukte. Tähtsamate kiudainete kromatogrammid on toodud joonisel 2 ja 4. Kromatogrammidel esinevate suuremate ja iseloomulikumate piikide asukohad on ära toodud tabelis 1, kusjuures piikide kaugused pürolüüsi algusest on antud bensooli suhtes, võttes bensooli retentsiooniajaks 100 . Kuna piik 1 märgib mitmeid produkte ja esineb kõikidel pürolüüsi kromatogrammidel, siis ei ole tabelis 1 toodud tema retentsiooniaegu.

Looduslikest ja nende baasil saadud keemilistest kiududest annavad puuvill ja viskoos ühesuguseid kromatogramme, mida iseloomustavad piigid 2, 3, 4, 5 ja 8 (vrd. joon. 4: A ja B). Eelmistega võrreldes annab atsetaat (joon. 4: C) kromatogrammi lōpul ühtelangeva piigi, piigid 2,4 ja 5 võimaldavad eraldada atsetaati viskoosist ja puuvillast.

Looduslikud valkkiud vill ja siid (joon. 4: D ja E) annavad ühesuguse kromatogrammi, kui mitte arvestada, et siidi kromatogrammis puudub villa puhul esinev piik 3.

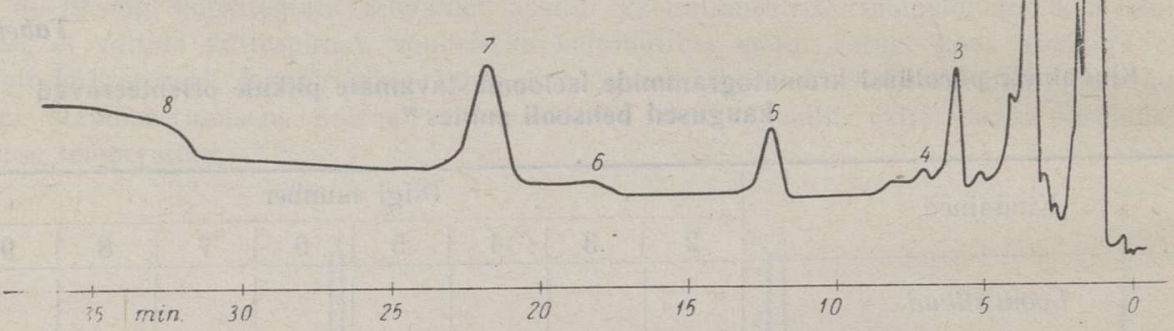

Joon. 3. Vinooli pürolüüsi kromatogramm. Kolonni pikkus $3 \mathrm{~m}$, täidiseks polüetüleenglükool 4000 / diatomiittellís $(50-70$ mesh).

Joonisel 4 on toodud ka vinooli, lavsaani ja nitroni pürolüüsi kromatogrammid. Vinooli iseloomustavad piigid $2,3,5$ ja 7 . Peale selle esineb veel rida väiksemaid piike, mis antud tingimustel ei ole küllalt iseloomustavad. Lavsaanile on iseloomulikud piigid 2 ja 5. Nitronit iseloomustab piikide rühm, kuhu kuuluvad piigid $3-5$.

Polüetüleen ja polüpropüleen (joon. 2: A ja B) annavad kromatogrammi algul ühtelangevaid piike. Erinevus ilmneb kromatogrammi lōpuosas (piigid 8 ja 9). Polüpropüleenile on iseloomulikuks piik 6 , mis iseloomustab kvantitatiivselt enamtekkinud produkti ning võimaldab eraldada polüpropüleeni polüetüleenist.

Kõiki pürolïüsitud polüamiidkiude (kapron, aniid, önant) iseloomustavad madalad piigid 2,3 ja 4 koos halvasti eraldunud väikeste piikidega piik 1 juures (joon. 4 : I, K, L).

Kloriini (joon. 4: M) iseloomustab gaasiliste produktide vähesus koos piikidega 3 ja 4 .

Kasulatud meetodil on võimalik $20 \mathrm{~min}$. jooksul kvalitatiivselt kindlaks määrata analüüsitava kiudaine liik.

Vaatamata mōningatele erinevustele, ei olnud antud tingimustel vōimalik vahet teha ühte rühma kuuluvate kiudude vahel, nagu kapron, önant ja aniid ning vill ja siid.

Samuti ei saa vahet teha looduslike ja keemiliste tsellulooskiudude vahel nagu puuvill ja viskoos.

Pikema retentsiooniajaga produktide juures täheldati retentsionniajas köikumisi. mistôttu piigi asukoha määramisel on mōningal juhul kasutatud mitme katse keskmist. Arvestades seda, võib pürolüüsi reprodutseerimisel esineda kōrvalekaldumisi tabelis 2 toodud arvulistest suurustest, kuid kromatogrammi üldpilt siiski ei muutu. 

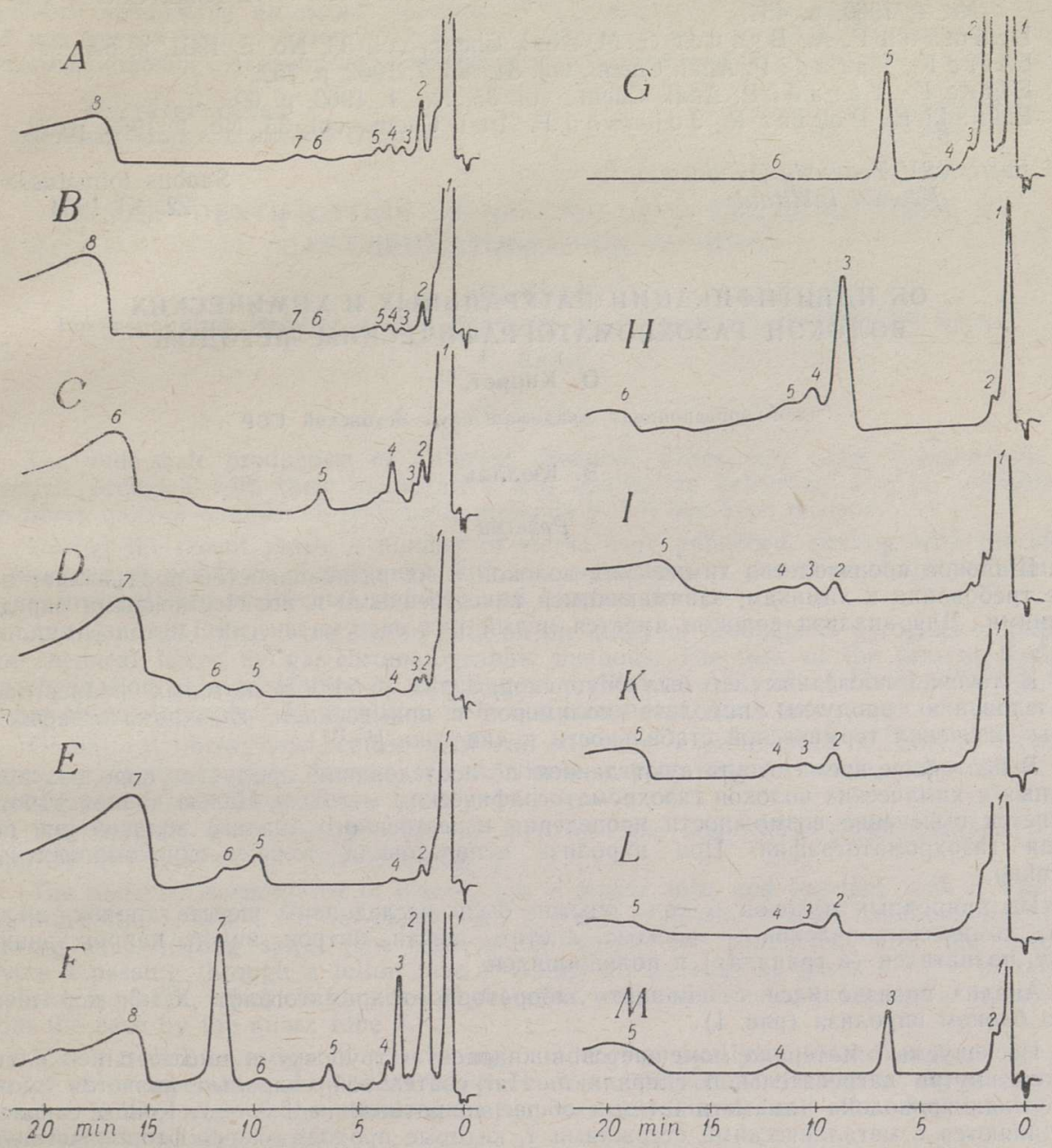

Joon. 4. Pürolüüsi kromatogrammid, kolonni täidiseks polüetüleenglükool $4000 /$ diatomiittellis: A - puuvill, B - viskoos, C - atsetaat, D - vill, E - siid, F - vinool, $\mathrm{G}$ - lavsaan, H - nitron, I - kapron, $\mathrm{K}$ - aniid, L - önant, $M$ - kloriin.

Seega võimaldab käesolev meetod kiiresti ja minimaalset aine kogust kasutades kindlaks määrata uuritava kiudaine kuuluvuse ühte või teise kiudainete liiki. Samuti võimaldab kirjeldatud meetod alati võrrelda analüüsitavat kiudu etaloonkiuga ükskõik missugustes tingimustes ja missuguseid kromatograafilisi kolonne kasutades.

\section{K I R J A N D US}

1. Ulrich H. M. Handbuch der chemischen Untersuchung der Textilfaserstoffe. I Band, Wien-Springer-Verlag, 1954.

2. $K$ л айн Г. Аналитическая химия полимеров. М., Нздательство нностранной лнтературы, 1963.

3. Koch P.-A., Wa g ner E. Textile Prüfungen, Dr. Spohr-Verlag, Wuppertal-Elberfeld, 1959.

4. Lehrle R. S., R o b b J. C. Nature, vol. 183, No. 4676,1959, p. 1671.

5. Ra de 11 E. A., Strutz H. C. Anal. Chem., vol. 31, No. 11, 1959, p. 1890.

6. Hew itt G. C., Whith a m B. T. The Analyst, vol. 86, No. 10, 1961, p. 643. 
7. Strassburger J., Bra uer G., Tr yon M., Forzi ati A. Anal. Chem., vol. 32 Nr. 4,1960 , p. 454.

8. L e hm a n n F. A., Br a uer G. M. Anal. Chem,, vol. 33, No. 6, 1961, p. 673.

9. E t tr e K., V a r a d i P. Anal. Chem., vol. 34, No. 7, 1962, p. 752.

10. Ettre K., V a r a di P. Anal. Chem., vol. 35, No. 1, 1963, p. 69.

11. B a r a 11 E., Porter R., John s on F. Anal. Chem., vol. 35, No. 1, 1963, p. 73 Eesti NSV Teaduste Akadeema
Keemia Instituut
Saabus toimetusse 22. XI 1963

\title{
ОБ ИДЕНТИФИКАЦИИ НАТУРАЛЬНЫХ И ХИМИЧЕСКИХ ВОЛОКОН ГАЗОХРОМАТОГРАФИЧЕСКИМ МЕТОДОМ
}

\author{
о. Қнррет,
}

член-корреспондент Академии наук Эстонской ССР

\section{Э. Кюллик}

Резюме

Широкое производство химических волокон и их разновндностей предъявляет новые требования к химикам, занимающимся качественными и количественными определениями. Для анализа волокон имеется целый ряд систематических методов анализа $[1,2,3]$

В течение последних лет был опубликован ряд работ, в которых подверглись исследованию продукты пиролиза полимеров с применением газохроматографни с целью изучения термической стабильности н кннетики [ ${ }^{4-11]}$.

В настоящее время отсутствуют данные по нсследованию продуктов пиролиза природных и химических волокон газохроматографнческим методом. Целью данной работы является выяснение возможности проведения качественного анализа волокон при помощи газохроматографии. При пиролизе использовалн только однокомпонентные волокна.

Из природных волокон в ходе опытов были исследованы шерсть хлопок, шелк, а из химических волскон - вискоза, ацетат, лавсан, нитрон, винол, капрон, энант, анид, полиэтилен (в гранулах) и полипропилен.

Анализ производился с помощью лабораторного хроматографа ХЛ-3, дополненного блоком пиролиза (рнс. 1).

Исследуемый материал помещается в кварцевую трубочку и вместе с ней вдвигается внутрь нагревательной спирали 5. Нагревательной спиралью является хромникелевая проволока (диаметр 0,4 мм, общее сопротивление 3,0 ом). Концы спирали соединяются с металлическими стержнями 4 , которые проходят через фторопластовую пробку 3. По ходу газов поставлен фильтр из измельченного кирпича, отделенный с концов медными сетками 8. Спираль изолирована от корпуса кварцевой трубкой 7.

Исследуемое вещество $(5-10$ ма) подвергалось пиролизу в среде газа-носителя до температуры $900^{\circ}$ в течение 60 cек. В конце каждого анализа вводили в качестве эталонного вещества бензол, время удерживания которого было взято за 100.

При анализе продуктов пиролиза пользовались колонкой длиной $2,0 \quad \mu$, внутренним диаметром 2,8 мм. В качестве наполнителя был использован полиэтиленгли. коль 4000/диатомитовый кирпич (50-70 меш). Количество жидкой фазы равно $20 \%$. Скорость течения газа-носителя гелия 50 мл/мин. Температура в колонке $100^{\circ}$.

В предварительных опытах использовались более длинные 3-метровые колонки, с помощью которых было достигнуто лучшее разделение, но в то же время увеличилась и продолжительность анализа (рис. 3).

При ислользовании в качестве наполнителя «Твээн 85»/«Хромосорб. W» были получены менее характерные пики (рис. 2: С).

Хроматограммы, характеризующие волокна, приведены на рнс. 4

Из природных волокон характерную хроматограмму дает хлопок.

Хроматограммы шелка и шерсти имеют минимальную разницу и поэтому при дашных условиях нх невозможно отделить.

Из химических волокон отличимы друг от друга полиэтилен и полипропилен (рис. 2: А, В), винол, лавсан, нитрон, хлорнн (рис. 4: $\mathrm{M}$ ), ацетат и группа полиамидных волокон (рис. 4).

С помощью данной колонки не удалось дифференцировать отдельные представнтели полиамидов - капрон, анид н энант. 
Таким об́разом, данный метод позволяет за короткое время, при наличии мини мального колнчества вещества, установнть прннадлежность исследуемого вещества к той нли другой группе волокон. Описанный метод позволяет также сравнивать анализируемые волокна с эталонным волокном при любых колонках и в разлнчных условнях.

Ннститут химии

Академии наук Эстонской ССР
Поступила в редакцию 22. XI 1963

\title{
ON THE IDENTIFICATION OF NATURAL AND CHEMICAL FIBRE BY GAS-CHROMATOGRAPHIC METHODS
}

\author{
O. Kirret, \\ Corresponding Member of the Academy of Sciences of the Estonian S.S.R.
}

E. Küllik

\section{Sumniary}

The wide-scale production of different chemical fibres sets new requiraments to chemists occupied with their quantitative and qualitative definition. For an analysis of the fibres quite a number of systematic methods $\left[1,2,{ }^{3}\right]$ has been devised.

i) uring the recent years, a number of works were published, dealing with the study of products of pyrolysis of polymers with an application of gas-chromatography, aiming at an investigation of thermal stability and kinetics $\left[{ }^{4}-11\right]$.

At the present time there are no data on the study of products of pyrolysis of natural and chemical fibres by gas-chromatographic methods. The task of the present work is the elucidation of a possibility of effecting a qualitative analysis of fibres with the help of gas-chromatography. At pyrolysis, only one-component fibres were used.

Of natural fibres, wool, cotton-wool and silk were experimented on, and of chemical fibres - viscose, acetate, lavsan, nitron, vinole, capron, enante, anide, polyethylene (in granules) and polypropylene.

The analysis was effected with the help of the laboratory chromatograph XJ-3 supplied with a block for pyrolysis (fig. 1).

The material investigated is placed into a quartz tube and together with it into the heating spiral 5 , with a chrome-nickel wire $(0.4 \mathrm{~mm}$ in diameter, total resistance $3.0 \mathrm{Ohm})$ serving as a heating spiral. The ends of the spiral are connected with the metallic pivots 4 passing through a teflon fuse 3 . Along the passage of gases a filter of refined firebrick is placed, which is bounded at the ends with copper nets 8 . The spiral is isolated irom the case by the quarz tube 7 .

The material investigated (5-10-mg) undergoes pyrolysis in the medium of gascarrier at a temperature of up to $900^{\circ}$ in the course of $60 \mathrm{sec}$. At the end of every analysis, benzene in the way of the standard matter was introduced, and the duration of it; retainment was taken as 100 .

At the analysis of the products of pyrolysis a column of $2.0 \mathrm{~m}$ in length and $2.8 \mathrm{~mm}$ in inner cross-section was used. The filling matier was polyethyleneglycol $4000 /$ firebrick $(50-70 \mathrm{mesh})$. The amount of the liquid phase was $20 \%$. The velocity of the flow of the gas-carrier, helium, was $50 \mathrm{ml} / \mathrm{min}$. The temperature in the column was $100^{\circ} \mathrm{C}$.

In preliminary tests columns of $3 \mathrm{~m}$ in length were used, which afforded a better division, but at the same time the duration of the analysis was prolonged (3).

At using a "Tween $85 " /$ "Chromosorb W" in the case of a filter, less typical peaks (fig. 2) were obtained.

The chromatogrammes characterizing the fibres investigated are presented in fig. 4.

of natural fibres, cotton wool yields the most characteristic chromatogramnic.

The chromatogrammes of silk and wool present only very slight differences, and in the given conditions they cannot be differentiated.

Of chemical fibres it is possible to differentiate from each other polyethylene, polypropylene (fig. 2: A, B), vinole, lavsan, nitron, chlorine (fig. 4: $\mathrm{M}$ ), acetate, and the group of polyamidic fibres (fig. 4).

With the help of the column applied it was not possible do differentiate some separate representatives of polyamides: capron, anide, enante.

Thus the given method allows to state within a short time and in the presence of a ninimal quantity of material, the belonging of one or another substance to one or another fibre group. It also permits a comparison of the fibres analysed with the standard one with the use of any columns and in different conditions. 